\title{
Menace of schistosomiasis: its true neglected nature in Nigeria
}

\begin{abstract}
Nigeria's growing population remains vulnerable to schistosomiasis. In view of little or no actively planned control programmes for schistosomiasis in Nigeria, it has become a 'come to stay' disease. Schistosomiasis affects virtually all populations, but worst in children that indulge in indiscriminate water-contact activities (like wadding, swimming). Six Schistosoma species can cause human infections: S. haematobium, S. mansoni, S. japonicum, S. intercalatum, S. mekongi, and S. guineensis; but S. haematobium and S. mansoni are the predominant causes of the disease. Human adults who practice unprotected irrigation farming, fishing, washing, or fetching of water from cercariae-infested water bodies or use such water for domestic chores are prone to schistosomiasis. The disease impacts health and development of Nigerian children. Anaemia, bladder cancers, haematuria, proteinuria, poor growth and low academic performances are evident among infected children. A good fraction of the Nigerian population is mostly unaware of the risks of transmission of schistosomiasis via cercariae-infested water bodies and hence more infections occur. It will cost less to prevent and control schistosomiasis than to treat and manage the infection. Therefore, there is an urgent need for implementation of other effective control measures other than administration of Praziquantel alone. Snail control, provision of safe water, good sanitation system and adequate creation of awareness will be vital for prevention and control of schistosomiasis in Nigeria.
\end{abstract}

Keywords: schistosomiasis, Nigeria, sanitation, children, complications, poverty, water, risk, health, government
Volume 6 Issue 5 - 2017

\author{
Henry Gabriel Bishop \\ Department of Microbiology, Nigeria
}

Correspondence: Henry Gabriel Bishop, Department of Microbiology, Faculty of Life Sciences, Ahmadu Bello University, Zaria, Nigeria, Tel +2348I76357626,

Email gabrielhenrybishop@gmail.com

Received: October 04, 2017 | Published: November 27, 2017
Abbreviations: NTDS; neglected tropical diseases; WHO; world health organization; US CIA; united states central intelligence agency; GSA; global schistosomiasis alliance

\section{Introduction}

\section{Nigeria and its position on neglected tropical diseases (NTDs)}

Nigeria has a total land mass of 923,768 square kilometers (but water occupies $13,000 \mathrm{sq} \mathrm{km}$ ) with over $181,562,056$ people belonging to over 250 ethnic groups. Children of age $0-14$ years make $43.01 \%$ of the entire population structure. It has about $70 \%$ people living below poverty line and life expectancy is 53.02 years. ${ }^{1,2}$ The country is now been referred to a 'ground zero' due to its high prevalence of neglected tropical diseases (NTDs). It has the greatest number of schistosomiasis cases (of both intestinal and urinary forms). For risk distribution of schistosomiasis, low risk is considered to be $\geq 1 \%$ to $<10 \%$, medium risk is considered to be $\geq 10 \%$ to $<50 \%$ and high risk is considered to be $\geq 50 \%{ }^{3}$ Schistosomiasis is one of the ten tropical diseases that have been targeted for control through special program for research and training in tropical diseases supported by United Nations Development Program, World Bank and World Health Organization. ${ }^{4}$ Over one billion people (i.e., about one-sixth of the entire world's population) are affected by one or more forms of NTDs while two billion individuals are at risk, especially among the tropical and subtropical countries. ${ }^{5}$ Nigeria's health-related and environmental problems vary with the socio-economic development achieved by individual states, towns and villages within them. The health problems are linked to poverty, inadequate water supply, lack of sanitation services and poor housing conditions. Hence, children, pregnant women, lactating mothers and the aged people are vulnerable to many diseases. Schistosomiasis is still a major public health problem. ${ }^{6}$

\section{Discussion}

History of schistosomiasis and earliest reports in Nigeria, Schistosomiasis is one of the world's oldest diseases of mankind. ${ }^{7}$ It is one of the most devastating NTDs with large economic and health consequences. ${ }^{8}$ It has been described as a 'major public health problem' affecting tropical and sub-tropical nations. Schistosomes are one of the nearly 300 species of parasitic worms found in human hosts. ${ }^{9}$ Over 700 million people dwell in areas endemic for schistosomiasis; the disease is endemic in Nigeria, as well as in Ethiopia, Congo, Kenya, Tanzania, Cameroon, Uganda, Malawi, Ghana, Mozambique, among others. ${ }^{8}$ Nigeria is thought to be the most schistosomiasis-endemic African nation. ${ }^{10}$ Even though, Theodor Bilharz first described the parasitic infection called bilharzia in the year $1851,{ }^{4}$ it was not until 1908 when the first case of bilharzia was reported in Nigeria and thought to be more widespread than ever contained in records. It was only by 1922 when physical deterioration and pains were associated with the disease. ${ }^{11}$ Nigeria's growing population remains vulnerable to schistosomiasis. In view of little or no actively planned control programmes for schistosomiasis in Nigeria, it has become a 'come to stay' disease. Schistosomiasis affects virtually all populations, but worst in children and adults practicing unprotected irrigation farming. The first map out project for schistosomiasis in Nigeria was in 1963, three years after its independence-with indications of major endemic zone in the south and minor endemicity in other areas of the country. 12,13

\section{Prevalence of schistosomiasis in Nigeria}

In the face of poor control strategy, schistosomiasis stems as one 
of the most common parasitic disease especially in the sub-Saharan African ${ }^{7}$ majorly due to conditions of poverty, lack of safe water supply and poor sanitation. ${ }^{6}$ It was only recently, on 4th June 2015, that Nigeria's Federal Ministry of Health officially released for the first time the prevalence report on schistosomiasis in Nigeria. The country has about 24 million people at risk of schistosomiasis with an overall prevalence of $9.5 \% .{ }^{14}$ There are several prevalence and intensity reports on schistosomiasis from around the country; but prevalence and intensity of this infection increase with age and peaks in the 5-14years age group. ${ }^{15}$ Prevalence reports on schistosomiasis from different parts of Nigeria are presented in Table 1. Urinary schistosomiasis is a persistent health burden among Nigerian children. They are mostly unaware of the risks of transmission of schistosomiasis via cercariae-infested water bodies and hence more infections occur. ${ }^{16}$

Table I Prevalence reports of urinary schistosomiasis in children in Nigeria

\begin{tabular}{|c|c|c|}
\hline $\begin{array}{l}\text { Study Location } \\
\text { (State) }\end{array}$ & $\begin{array}{l}\text { Reported Prevalence of } \\
\text { Urinary Schistosomiasis }\end{array}$ & Researcher(s) \\
\hline Lere, Kaduna & $12.30 \%$ & Luka $^{46}$ \\
\hline Edo & $32.6 \%, 40.1 \mathrm{eggs} / \mathrm{I} 0 \mathrm{ml}$ & Nmorsi ${ }^{47}$ \\
\hline Bende, Abia & $42.30 \%$ & Alozie $^{48}$ \\
\hline Ezza-North, Ebonyi & $79.40 \%$ & Uneke $^{49}$ \\
\hline Abuja & $31.30 \%$ & Ifeanyi ${ }^{50}$ \\
\hline Ebonyi & $6.30 \%$ & Uneke $^{49}$ \\
\hline $\begin{array}{l}\text { Ukwelo-Obudu, Cross } \\
\text { River }\end{array}$ & $0.00 \%$ & Ingang-Etoh ${ }^{51}$ \\
\hline Abini, Cross River & $4.50 \%$ & Ingang-Etoh ${ }^{51}$ \\
\hline Abeokuta, Ogun & $58.1 \%, 1.17 \mathrm{egg} / \mathrm{I} \mathrm{ml}$ urine & Ekpo $^{36}$ \\
\hline Birni-Gwari, Kaduna & $36.00 \%$ & Alhassan ${ }^{52}$ \\
\hline Benue & $41.50 \%$ & Houmsou $^{53}$ \\
\hline Abarma, Zamfara & $74.00 \%$ & $\mathrm{Bala}^{54}$ \\
\hline Lagos & $78.40 \%$ & Oluwasogo $0^{55}$ \\
\hline Adamawa & $27.23 \%$ & Bigwan ${ }^{56}$ \\
\hline Enugu & $34.10 \%$ & Ossai et al..$^{57}$ \\
\hline Borno & $48.70 \%$ & $\mathrm{Bala}^{54}$ \\
\hline Bomo-Zaria, Kaduna & $19.50 \%$ & Omenesa $^{38}$ \\
\hline Kano & 8.3 & Dawaki et al..$^{37}$ \\
\hline Jaba, Kaduna & $12.3 \%, 2.69 \mathrm{egg} / 10 \mathrm{ml}$ urine & Bishop ${ }^{16}$ \\
\hline Osun & $51.10 \%$ & Hassan et al. ${ }^{58}$ \\
\hline Saki, Oyo & $32.70 \%$ & Salawu ${ }^{59}$ \\
\hline
\end{tabular}

\section{Complications of schistosomiasis}

Each form of schistosomiasis has particular pathologies associated with it. In urinary schistosomiasis, about $50 \%$ of the Schistosoma haematobium ova are not expunged from the urinary bladder but remain embedded in the tissues of the bladder wall. ${ }^{17}$ More serious complications ensue upon healing many years after than with active pathology. These may include fibrotic lesions, glomerulonephritis, amyloidosis and malignancy or cancer. ${ }^{18}$ Chronic schistosomiasis is a risk factor for nontyphi Salmonella infection and promotes development of squamous cell bladder cancer. ${ }^{19}$ Granulomata due to urinary schistosomiasis following healing are often associated with sandy patches or confluent fibrosis and calcification. This condition can affect bladder muscles and the ureteric walls, cause bladder dysfunction and disrupt internal vesical or ureterovesical sphincter. ${ }^{18}$ Urinary schistosomiasis exacerbates Salmonella infections and carrier states due to Salmonella Typhi and Salmonella Paratyphi. Chronic urinary schistosomiasis causes calculi (stones) in urinary tracts and bladders of the patient. Anaemia and impairments of growth/development are also associated with urinary schistosomiasis. ${ }^{19}$ Anaemia was found to increase in a population with schistosomiasis than in those not infected and the higher the level of the infection, the more the anaemia. ${ }^{16}$ Portal hypertension and central nervous system complications can occur due to schistosomiasis..$^{20}$ About $10.2 \%$ of appendicitis had been reported to be a result of complicated schistosomiasis. Such complications could be due to delayed diagnosis or misdiagnosis, which may prolong the course of treatment. ${ }^{21}$ though a lot, is known about clinical manifestations due to urinary and intestinal schistosomiasis, genital complications due to chronic urinary schistosomiasis is either ignored or partially understood. Schistosomiasis can affect the genitals especially in females, but it affects men too. It can extend into several complications in females like female genital schistosomiasis (FGS)where the cervix, endometrium and fallopian tubes can be affected. Abdominal and pelvic irritations are evident, leading to dyspareunia, leucorrhoea, cervicitis, dysmenorrhea, endomertritis, simple contact or post-coital bleeding or bleeding during examination and salpingitis. FGS can secondarily cause other complications like sudden abortions, ectopic pregnancy and infertility in females of child-bearing age. FGS can be caused by other species of Schistosoma, but S. haematobium is the main cause. FGS are not restrained to parasitic ill-health, it can increase the risk of contraction of HIV, most especially in regions endemic with the dual infections. ${ }^{22,23}$ In the men, evidences of genital schistosomiasis have presented in the form of epididymitis which is stimulatory for tuberculosis, funiculitis, painful micturition, prostatitis, laziness, fistulization and haemospermia. ${ }^{23}$ About one-third of women infected with Schistosoma haematobium develop genital disease; where vulvae and perinea involvement appear in forms of hypertrophy, ulcers, fistula, and warts. These could be mistaken for other forms of genital infections. ${ }^{4}$ characteristically; the cervical wall of the female on examination may have sandy patches, abnormally branched or circular blood vessels, papules and contact bleeding. ${ }^{4}$

\section{Diagnosis of schistosomiasis and advances made so far}

Not much advances are available yet. The detection of the Schistosoma eggs in stool or urine has remained the gold standard for its diagnosis, though sedimentation and concentration methods using formalin solution have aided detection of light infections., ${ }^{4,24}$ For intensity of the infection, light infection has $<50$ eggs $/ 10 \mathrm{ml}$ urine while heavy infection has $\geq 50$ eggs $/ 10 \mathrm{ml}$ urine. ${ }^{16}$ In places like China, miracidium-hatching test followed by microscopic visualization of hatched miracidia has been used for diagnostic purpose. Also, examination of biopsies from the bladder and rectal mucosa is employed. ${ }^{4}$ It is usually unnecessary to quantify the intensity of the infection before the administration of Praziquantel because its mere 
detection is diagnostic enough. The Kato-Karz stool thick smear requires about $40-50 \mathrm{mg}$ of stool (using methylene blue-stained cellophane soaked in glycerine or glass slides); its helps in quantitating egg burden in field researches and monitoring/control initiatives for intestinal Schistosomiasis. ${ }^{4,24}$ Chemical reagent strips have been used to detect microhaematuria in infected children, ${ }^{24}$ but in most endemic areas, the children present with visible haematuria. Though serological (antibody detection) have been developed, they are not so useful than in defining the regions of low intensity and poor detection of eggs in stool, urine or biopsies; this is because of prolonged positivity period in already cured patients. ${ }^{4,24}$ Some markers have been helpful in the complete diagnosis of schistosomiasis to include eosinophilia, anaemia (but may be due to iron-deficiency, chronic disease, or macrocytosis), hypoalbuminemia, elevated urea/creatinine levels, hypergammaglobulinemia, and splenomegaly., ${ }^{4,}$ For genital schistosomiasis, diagnosis is complete if Schistosoma eggs are found in genitals of females or males. Filtration techniques by use of nylon, paper filters or polycarbonate filters are of diagnostic value. ${ }^{23,24}$ Till now, laboratory method for confirmation of schistosomiasis is of low sensitivity; and because genital lesion due to Schistosoma eggs mimic cancerous infections (of vulvae, vaginas, cervices and endometria), sexually transmitted infections (STIs) and even urogenital tuberculosis, it is helpful to conduct differential diagnosis to enhance proper therapy. Hence, FGS is clinically diagnosed by visual inspection and histological examination ${ }^{23}$ Of recent, biochemical markers of hepatic fibrosis are currently being researched, because the serum levels of procollagen peptide (types III and IV), P1 fragment of laminin, hyaluronic acid, and fibrosin become elevated in infected individual suffering severe hepatic fibrosis and followed by subsidence after the administration of Praziquantel. ${ }^{4}$ For the growing cases of FGS, early diagnosis will be important to avoid irreversible damage to the female's urogenital and reproductive organs. Hence, for females presenting with urinary schistosomiasis, especially from endemic regions, diagnosis for FGS should be advocated.

\section{Treatments for schistosomiasis and advances made so far}

Schistosomiasis is both preventable and treatable. Single dose of Praziquantel per year can help control the disease. This can be best achieved through mass drug administration to school children and high risk communities. ${ }^{8,27}$ Because most people are often unaware of genital schistosomiasis, less medical attention has been given to it; consequently, misdiagnosis has resulted in false and ineffective therapy. ${ }^{4,2}$ There is also scant knowledge regarding proper treatment for FGS, mainly due to incorrect diagnosis. Wrong diagnosis of FGS can lead to dangerous and irreversible operations like ovarectomy, salpingotomy and hysterectomy instead of simple and safe therapy. To overcome this unacceptable challenge, awareness creation to health personnel and the general public in endemic zones (like Nigeria) will be valuable..$^{23}$ Upon confirmation of FGS, treatment with Praziquantel should be initiated. This drug will kill the adult worms, and consequently reduce the egg burden and also prevent the appearance of new FGS lesions in the urogenital wall. ${ }^{23}$

\section{Snail control strategy}

Schistosomes are the cause of schistosomiasis, whether intestinal or urinary form. Six species of Schistosoma infect humans, S. guineensis, $S$. haematobium, S. intercalatum, S. japonicum, S. mansoni and $S$. mekongi, but $S$. haematobium and $S$. mansoni are the predominant causes of the disease. ${ }^{28}$ Schistosomes require intermediates and definitive (human) hosts to continue their life cycles. The intermediate hosts are snails, (Bulinus africanus, B. truncatus, B. tropica and Physopsis species). However, the populations of snails in the tropics and subtropics have not been controlled. ${ }^{29}$ There has been less attention on control and possible eradication of the both the intermediate host and the agents. Curative treatment alone is not enough to control or eradicate schistosomiasis in Nigeria, the rest of Africa and the entire world by proposed 2020. One of the baseline problems facing incompetence in the control/eradication of schistosomiasis is lack of effective 21 st Century policies, where lawmakers hardly understand what schistosomiasis really is or what it is capable of causing to an average person. ${ }^{30}$ To raise a substantial control goal, an expanded scope of schistosomiasis assessment is needful, detailing who needs treatment, the nature of medications, where and when, provision of aids and accessing the remote locations of Nigeria. Control will not be achievable without appropriate knowledge of prevailing prevalence of the disease. Quite a number of prevalence reports are surging around the country. Hence the Nigerian problem now is not that of information, but responsive approaches to the available data. Control should be taken, first, at the community level which is the very source of morbidity, and then regional eradication can be aimed. Such approaches will accelerate good plans for national eradication. Researchers have long been conducted on ended plant as a cheap molluscide to control the snails that transmit Schistosomiasis, ${ }^{31}$ but not a considerable control of snails has been achieved in most parts of Africa, and Nigeria in particular. The role of biotechnology in control of major disease in the world cannot be over emphasized. ${ }^{31}$ Currently there are no practically-available control measures against snails in Nigeria. Hence, this is a wake-up call to researchers.

\section{Impacts of schistosomiasis}

People infected with NTDs like schistosomiasis and intestinal worms are often unable to work or attend school-resulting in an endless cycle of economic hardship. Hence, children are affected by growth stunting, weakness, fatigue and learning difficulties. ${ }^{8}$ Only about $50 \%$ of ova laid by female schistosomes get excreted in stool (for S. mansoni, S. japonicum, S. mekongi and S. intercalatum) or in urine (for $S$. haematobium), the other half cause local damage and organ dysfunctions due to their acute and chronic inflammatory reactions upon entrapment in host's tissues. ${ }^{30}$ At first exposure, symptoms may not be pronounced; but rashes, itching and flu-like symptoms may be witnessed by some individuals. Treating these diseases is critical to reducing poverty and boosting economic prosperity ${ }^{14}$ Schistosomiasis is a chronic debilitating disease affecting human population. ${ }^{32}$ Schistosomiasis is not an asymptomatic infection. It has been re-emphasized by King that schistosomiasis in its nature is truly a chronic inflammatory disease of the intestines, urinary tract or organs since eggs of Schistosoma spp cause inflammation and damage of tissues due to immune-mediated reactions. Schistosomiasis causes economic and health burdens by disabling a sufferer, as well as leads to death of between $14,000^{33}$ to estimated 200,000 per year ${ }^{24-31}$ Intestinal schistosomiasis causes damage to intestines, liver. Urinary schistosomiasis is largely associated with bladder cancer development. In some rare events, the brain and spinal cord may be invaded with eggs of schistosomes, resulting in seizures, paralysis and inflammation of the spinal cord. In the tropical regions, urinary schistosomiasis commonly causes haematuria, especially among teenage boys. Such infected individual, as the case of four Canadian children who visited Nigeria, may develop secondary bacterial cystitis and other urinary structural lesions. ${ }^{34}$ Hence this may scare tourists and 
diplomats from touring our rich cultural sites or visiting our country for economic and political ties. Acute schistosomiasis had been found to be a problem especially to travellers from non-endemic nations into Africa. ${ }^{4}$ Affected children suffer from stunted growth, impaired cognitive development, malnutrition, anaemia, disrupted school attendance and performance. It is not limited to severe damage on the bladder, kidneys, liver, and intestines but hinders people's ability to work and contribute to societal development. ${ }^{35}$

\section{Affected populations}

Any individual (including children, adolescents, women and men) can be affected by schistosomiasis provided there is contact with cercariae-infested water. Travellers from non-endemic countries into endemic zones also stand at risk, especially when the same unsafe water is used for bathing or other domestic activities. Children between the ages of 5-10 have the highest risk of schistosomiasis and intestinal worms. Men are also more likely to get infected that women. ${ }^{14}$ Neglected tropical diseases flourish under conditions characterized by poor housing and sanitation, unsafe water, and limited access to basic health care. They cause great human misery-pain, disfigurement, mental and physical disabilities, with death records of about 500,000 per year. NTDs often lead to social stigmatization and discrimination, especially for children, women and persons with disabilities. NTDs hinder development, keeping individuals and communities trapped in a cycle of poverty, and negatively impact almost all millennium development goals. ${ }^{5}$ In the year 2013, an estimated total of 261,000,019 people globally required treatment for schistosomiasis, and out of this number $46.4 \%$ were school-age children of 5-14years of age. Yet, $92 \%$ of those that required treatment in 2013 were from Africa. However, this success in reducing the morbidity of schistosomiasis in Africa cannot be maintained if the aspects of safe water supply, sanitation, education, and snail control and awareness creation are neglected. ${ }^{28}$

\section{Why the continued menace of schistosomiasis?}

Distribution and transmission of schistosomiasis are dependent on availability of some specific snail (intermediate) hosts and certain human (cultural) activities in conditions of poor sanitation, environmental alterations, unsafe water supply, and migration. ${ }^{28}$ The first problem promoting the continued spread of schistosomiasis in Nigeria is that of poverty. Poverty remains key in the transmission of schistosomiasis, yet this is often not mentioned in governmental policies and planning. Coupled with poverty is the lack of adequate sanitation and rural-to-urban population drift. ${ }^{30}$ The disease has been described as a disease of the poor, ${ }^{14}$ and over $70 \%$ of the country's population dwells in poverty. ${ }^{1,2} \mathrm{~A}$ large proportion of the population lack access to safe water; they are forced to use the available unsafe streams, lakes, rivers, ponds and other seasonal stagnant water bodies for domestic and agricultural purposes. The second possible factor is poor sanitation network, where excrements and humans wastes are indiscriminately disposed into water sources, aiding the spread of disease agents and vectors. Juvenile activities include indiscriminate activities in water bodies, mainly (unsafe) streams, rivers, ponds, stagnant waters, marshy fields. This situation increases their chances of coming in contact with Schistosoma cercariae. The cercariae are always attracted to human body due to their sensation to wave vibrations, chemicals, obstructed light patterns in the water and they swim upward toward the source of such inducers. ${ }^{17}$ In general, young children and adults may acquire the infection via any of the following routes, bathing of younger children with water fetched from infested streams by their mothers, but older children visit the streams by themselves to either fetch water, wash, bathe or swim. ${ }^{36}$ This situation has been rightly defined to constitute a poor and neglected concept toward proper knowledge, attitude and practice in the management of the disease.${ }^{37}$ Hence, the problems of unawareness and/or illiteracy still persist in Nigeria and more NTDs are been reported every year. When people are not aware of harmful things, they cannot protect themselves against them! But ignorance is no excuse. Agencies and the government should be saddled with the duty of creating awareness at local and federal levels in the country. A closer attention should be drawn into vaccine production against Schistosoma $\mathrm{spp}^{22}$ and proper education will reduce the menace of the disease. ${ }^{38}$

\section{Intervention bodies and agencies}

Nigeria's Ministry of Health has developed a five-year NTD Master Plan for the prevention, treatment, control and elimination of NTDS by the year $2020,{ }^{15}$ this is also in line with the WHO's 2020 targeted the elimination of schistosomiasis. Much is yet to be done to overcome the threats pose by parasitic diseases in the tropical and sub-tropical countries. Nigeria is one of countries in Africa with the highest burdens of diseases which were why the Carter Center was invited in 1988 to help eradicate Guinea worm. More health programmes were further imitated by the Carter Center; the Carter Center's Schistosomiasis Control Program is assisting in the control of schistosomiasis in Delta, Ebonyi, Edo, Enugu, Nassarawa and Plateau state, basically integrated treatments. It is anticipated that millions of Nigerians will be spared from neglected diseases like schistosomiasis, Guinea worm, lymphatic filariasis, river blindness, trachoma and malaria. ${ }^{2}$ Non-profit organization like MITOSATH is working to see that Nigeria is released from the burden of NTDs. The END7 funds have supported such campaigns in Bauchi State. ${ }^{14}$ There are many other organizations supporting the fight against schistosomiasis in Nigeria. They include Izumi Foundation, Envision, Sight Savrs, DFID and Children's Investment Fund Foundation; ${ }^{3}$ all these have raised our hope for elimination of the disease in Nigeria in no long time from now. Schistosomiasis among other NTDs are strongly associated with poor economy, hence control and elimination of NTDs are paramount for the realization of the Sustainable Development Goals (SDGs) in Nigeria and her quest to be one of the 20 major economic nations globally by 2020 with a popular mantra of Vision $20,2020 .{ }^{14}$ Though control measure for schistosomiasis in Nigeria has been on mass treatment with Praziquantel, attention had been raised for its nonavailability for the pre-school children. ${ }^{36}$ Many areas in Nigeria have been mapped out in the control initiative (Figure 1).

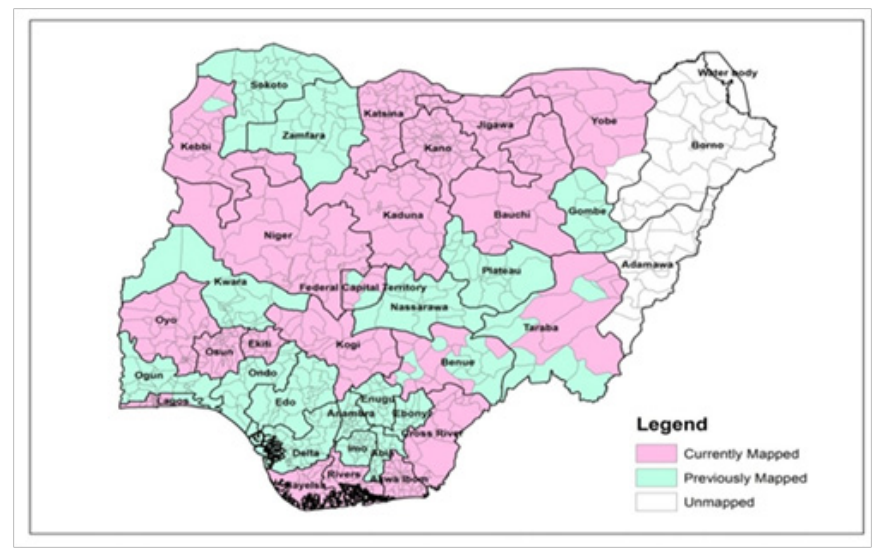

Figure I Schistosomiasis mapped project areas in Nigeria. 


\section{Targeted elimination}

Health education is a key element for schistosomiasis control. Most Nigerians from the rural and parts of urban areas depend largely on rivers and ponds prone to open defecation and urination. Communitybased administration of Praziquentel ( $40 \mathrm{mg} / \mathrm{kg}$ as a single dose) will help to reduce the burden of the disease. ${ }^{2}$ Many more individuals and bodies are rallying supports for the elimination of NTDs. For example, following the Third Progress Report of the London Declaration, many bodies have responded on the need for concerted efforts in the elimination of these tropical diseases that have plagued sub-Saharan countries. Global Schistosomiasis Alliance (GSA) has called also upon both governments and international bodies to support this fight against NTD through commitments and mobilizing of resources. ${ }^{8}$ With an estimated annual deaths of 200,000 due to schistosomiasis, this menace is yet preventable because control strategies and well known, inexpensive and accessible. ${ }^{8}$ Nigeria is the largest recipient of Praziquantel donation by a company called Merck as part of support to WHO in the fight against schistosomiasis in Africa. ${ }^{39}$ Praziquantel has been safely co-administered with Albendazole and Ivermectin in areas where these drugs have been used separately for preventive chemotherapy. Regular and undelayed administration of Praziquantel at young (childhood) age can prevent the progression of schistosomiasis into genital damage and further complications. This is why WHO has been advocating and promoting routine mass drug administration in high risk communities and its availability in all health facilities. Praziquantel is the drug of choice in this advocacy; it kills the adult worms-providing relief to sufferers and regression of inflammatory lesions. ${ }^{23}$ Some areas in Nigeria especially the NorthEast is unmapped for schistosomiasis (Figure 1).

Increasing resistance to praziquantel: it is well known that the anti-parasitic drug, Praziquantel, is the only effective drug against schistosomiasis worldwide ${ }^{7}$ but in African another drug, Trichlorfon is also administered. ${ }^{40}$ Some reports are coming up of reduced curative ability against schistosomes, especially in the African continent. It means therefore the schistosomes are gradually developing some level of resistance against the drug. ${ }^{7,43}$ This is a sure gradual indication that the most indispensable drug in the curative treatment of schistosomiasis may be a failure if no newer drugs and actions strategies are being looked for. ${ }^{44,45}$ This threat of resistance of schistosomes to Praziquantel reduces the hopes of its eradication by the year 2020. Some notable causes of ineffectiveness of Praziquantel have been deduced to include immaturity of schistosomes as at the time of commencement of treatment, emergence of resistant strains especially in Africa were the drug is most used, and possible reinfection. ${ }^{7}$ One irreversible problem is that once the bladder wall is infested with actively feeding schistosomes and their eggs, prognosis becomes poor and survival of patient becomes slim. ${ }^{40}$

\section{Conclusion}

Schistosomiasis is endemic in Nigeria. Its menace on children's health is alarming but often not talked about. Firstly, efforts should be made on creation of awareness about the disease in every area of the nation. Parents and school teachers must ensure that children are not allowed to bathe in unprotected water bodies. The government should embark on good health policies through provision of safe water to communities. School curriculum should contain aspects of diseases that affect the health of the citizens.

\section{Acknowledgements}

None.

\section{Conflicts of interest}

The author hereby declares that there is no any financial interest or any conflict of interest in this work.

\section{Funding}

None.

\section{References}

1. The World Fact Book. Africa: Central Intelligence Agency; 2016.

2. Waging peace, fighting disease, building hope-Nigeria. Georgia: The Carter Center; 2016.

3. Schistosomiasis Control Initiative, Nigeria, UK: Imperial College of London; 2016.

4. Allen GR, Paul BB, Adrian CS, et al. Schistosomiasis. $N$ Engl $J$ Med. 2002;346(16):1212-1220.

5. NTD Report Neglected Tropical Diseases. Germany: CBM; 2015;1-12.

6. Johannesburg Summit, Nigeria: country profile (Chapter 6). CPNIGERIA. 2002;1-77.

7. Olajide AO, Olajide FO, Aremu AA, et al. Ureteric obstruction secondary to schistosomiasis 2 years after Praziquantel therapy: a case report. Pan Afr Med J. 2012;12:32.

8. Global Schistosomiasis Alliance. Merck, Germany. 2016.

9. Cox FE. History of Human Parasitology. Clin Microbiol Rev. 2002;15(4):555-612.

10. Chitsulo L, Engels D, Montresor A, Savioli L. The global status of schistosomiasis and its control. Acta Trop. 2000;77(1):41-51.

11. Farley J. Bilharzia, a history of imperial tropical medicine, Chapter 12, Part III. Cambridge University Press, UK. 1991;219-232.

12. CEGET-CNRS/OMS-WHO. Nigeria: Atlas of the global distribution of schistosomiasis. 1987;1-7.

13. Jones I. History of Schistosomiasis in Nigeria. Stanford University, USA. 2015;1-2.

14. Global Network Neglected Tropical diseases. Government of Nigeria releases new data on the prevalence of schistosomiasis and intestinal worms. SABIN: Vaccine Institute, USA. 2015.

15. Hotez PJ, Asojo OA, Adesina AM. Nigeria: "Ground Zero" for the high prevalence neglected tropical diseases. PLoS Negl Trop Dis. 2012;6(7):e1600.

16. Bishop HG, Inabo HI, Ella EE. Prevalence and intensity of urinary schistosomiasis and their effects on packed cell volume of pupils in Jaba LGA, Nigeria. Edorium J Microbiol. 2016;2:13-26.

17. Schistosomiasis. Infection Landscapes, USA. 2012.

18. Elbaz T, Esmat G. Hepatic and intestinal schistosomiasis: review. $J$ Adv Res. 2013;4(5):445-452.

19. Cheesbrough M. District Laboratory Practice in Tropical Countries. $2^{\text {nd }}$ edn, Cambridge University Press, UK. 2006;1-454.

20. Leder K, Weller PF. Epidemiology pathogenesis and clinical features of schistosomiasis, UpToDate. 2011

21. Botes SN, Ibirogba SB, Mc Callum AD, et al. Schistosoma prevalence in Appendicitis. World J Surg. 2015;39(5):1080-1083.

22. Brindley PJ, Hotez PJ. Break out: urogenital schistosomiasis and Schistosoma haematobium infection in the post-genomic era. PloS Negl Trop Dis. 2013;7(3):e1961. 
23. Genital manifestations of schistosomiasis. Africa: WHO. 2016.

24. WHO. Schistosomiasis. Africa: Mediacentre: Factsheets. 2016.

25. Fenwick A, Webster JP. Schistosomiasis: challenges for control, treatment and drug resistance. Curr Opin Infect Dis. 2006;19(6):577-582.

26. Nahum LA, Mourao MM, Oliveira G. New frontiers in Schistosoma genomic and transcriptomics. J Parasitol Res. 2012:849132.

27. King $\mathrm{CH}$, Bertsch D. Meta-analysis of urine heme dipstick diagnosis of Schistosoma haematobium infection, including low prevalence and previously-treated populations. PloS Negl Trop Dis. 2013;7(9):e2431.

28. WHO Schistosomiasis: number of people treated worldwide in 2013. Wkly Epidemiol Rec. 2015;90(5):25-32.

29. Assafa D, Kibru E, Nagesh S, et al. Ethiopia Public Health Training Initiative, Medical Parasitology Ethiopia. 2004;1-150.

30. King CH. The Causes and Impacts of Neglected Tropical and Zoonotic Diseases: Opportunities for Integrated Intervention Strategies. National Academies Press, USA. 2011.

31. Walgate R. Miracle or Menace? Biotechnology and the Third World. Panos Publications Ltd, UK. 1990;88-146.

32. Noble ER, Glem AN. Biology of Animal Parasites. $5^{\text {th }}$ edn, Lea and Febiger, USA. 1982;157-158.

33. Mohager MO, Mohager SO, Kaddam LA. The association between schistosomiasis and enteric fever in a single Schistosomaendemic area in Sudan. Int J Pharm Sci Res. 2014;5(6):2181-2184.

34. Sheehan GJ, Sekla L, Harding GK. Urinary schistosomiasis: a report of four cases and a review. Canad Med Assoc J. 1884;131(11):1361-1364.

35. Schistosomiasis-the rural killer. USA: The End Fund: Ending neglected Diseases. 2016.

36. Ekpo UF, Laja-Deile A, Oluwole AS, et al. Urinary schistosomiasis among preschool children in a rural community near Abeokuta, Nigeria. Parasit Vectors. 2010;3:58.

37. Dawaki S, Al-Mekhlafi HM, Ithoi I, et al. The menace of schistosomiasis in Nigeria: knowledge, attitude, and practices regarding schistosomiasis among rural communities in Kano State. PLoS One. 2015;10(11):e0143667.

38. Omenesa HO, Bishop HG, Raji HM. Prevalence of urinary schistosomiasis among pupils attending primary schools in Bomo Village, ZariaNigeria. International Journal of Research in Engineering and Science. 2015;3(5):14-19.

39. Chioma O. Our core responsibility is to combat schistosomiasis disease in Nigeria, others. Nigeria: Vanguard, 2015.

40. UNESCO-Nigeria Technical and Vocational Education Revitalization Project-Phase II: Course Code STB 212, UK. 2008.

41. Raso G, N'Goran EK, Toty A, et al. Efficacy and side effects of praziquantel against Schistosoma mansoni in a community of western Cote d'Ivoire. Trans R Soc of Trop Med Hyg. 2004;98(1):18-27.

42. Silva IM, Thiengo R, Conceicao MJ, et al. Therapeutic failure of praziquantel in the treatment of Schistosoma haematobium infection in Brazilians returning from Africa. Mem Inst Oswaldo Cruz. 2005;100(4):445-449.

43. Alonso D, Munoz J, Gascon J, et al. Failure of standard treatment with praziquantel in two returned travelers with Schistosoma haematobium infection. Am J Trop Med Hyg. 2006;74(2):342-344.
44. Caffrey CR. Chemotherapy of schistosomiasis: present and future. Curr Opin Chem Biol. 2007;11(4):433-439.

45. Doenhoff MJ, Cioli D, Utzinger J. Praziquantel: mechanisms of action, resistance and new derivatives for schistosomiasis. Curr Opin Infect Dis. 2008;21(6):659-667.

46. Luka SA, Ajogi I, Umoh JU. Schistosomiasis among school children in Lere Local Government Area, Kaduna State, Nigeria. Journal of Tropical Biosciences. 2015;10(66):57.

47. Nmorsi OPG, Egwunyenga OA, Okholo OE. Schistosoma haematobiuminfections in two rural communities of Edo State, Nigeria. Southeast Asian J Trop Med Public Health. 2001;32(3):570-574.

48. Alozie JI, Anosike J. Prevalence of urinary schistosomiasis in Ozuitem, Bende Local Government Area of Abia State, Nigeria. Animal Research International. 2004;1(2):77-80.

49. Uneke C, Ugwuoke-Adibuah S, Nwakpu K, et al. An Assessment of Schistosoma haematobium infection and urinary tract bacterial infection among school children in rural eastern Nigeria. The Internet Journal of Laboratory Medicine. 2009;4(1):1-6.

50. Ifeanyi CIC, Matur BM, Ikeneche NF. Urinary schistosomiasis and concomitant bacteriuria in the Federal Capital Territory Abuja Nigeria. New York Science Journal. 2009;2(2):1-8.

51. Ingang-Etoh PC, Essien UC, Amama SA, et al. Prevalence of urinary schistosomiasis among school children in Ukwelo-Obudu and Abini communities in Cross River State, Nigeria. Port Harcourt Medical Journal. 2009;3(3):451-452.

52. Alhassan A, Luka SA, Balarabe ML, et al. Prevalence of urinary schistosomiasis among school children in Birnin-Gwari Local Government Area, Kaduna State. Nigerian Journal of Scientific Research. $2013 ; 11 \& 12: 24-28$

53. Houmsou RS, Amuta EU, Sar TT. Profile of an epidemiological study of urinary schistosomiasis in two local government areas of Benue State, Nigeria. J Biomed Sci. 2012;1(1):39-48.

54. Bala AY, Ladan MU, Mainasara M. Prevalence and intensity of urinary schistosomiasis in Abarma village, Gusau, Nigeria: a preliminary investigation. Science World Journal. 2012;7(2): 1-4.

55. Oluwasogo OA, Fagbemi OB. Prevalence and risk factors of Schistosoma haematobium infections among primary school children in Igbokuta Village, Ikorodu North Local Government, Lagos State. IOSR Journal of Nursing and Health Science. 2013;2(6):62-68.

56. Bigwan EI, Kunihya RZ, John TJ. Epidemiological survey of urinary schistosomiasis among primary school children in Michika, Adamawa State, North-Eastern Nigeria. Int J Cur Res Rev. 2013;5(5):111-116.

57. Ossai OP, Dankoli R, Nwodo C, et al. Bacteruria and urinary schistosomiasis in primary school children in rural communities in Enugu State, Nigeria, 2012. Pan Afr Med J. 2014;18(Suppl 1):15.

58. Hassan AO, Amoo AOJ, Akinwale OP, et al. Current status of urinary schistosomiasis in communities around the Erinle and Eko-Ende Dams and the implications for schistosomiasis control in Nigeria. South Afr J Infect Dis. 2014;29(4):137-140.

59. Salawu AS, Asaolu SO, Sowemimo OA. Co-infections with Schistosoma haematobiumand soil-transmitted helminths among school-aged children in Saki, Oyo State, Nigeria. J Public Health Epidemiol. 2014;6(12):417423 . 